\title{
A EDUCAÇÃO AMBIENTAL NOS CURSOS SUPERIORES DE TECNOLOGIA DA ÁREA DE GESTÃO E NEGÓCIOS E NOS BACHARELADOS EM ADMINISTRAÇÃO
}

\author{
ENVIRONMENTAL EDUCATION IN TECHNOLOGY UNDERGRADUATE COURSES IN \\ BUSSINESS AND MANAGEMENT AREA AND ADMINISTRATION
}

\section{LA EDUCACIÓN AMBIENTAL EN LOS CURSOS SUPERIORES DE TECNOLOGÍA EN EL ÁREA DE GESTIÓN Y NEGOCIOS Y DE ADMINISTRACIÓN}

\author{
Ivan Maia Tomé ${ }^{1}$ \\ Diogo Martins Gonçalves de Morais $^{2}$ \\ Raquel da Silva Pereira ${ }^{3}$
}

\begin{abstract}
Resumo
O objetivo dessa pesquisa é evidenciar as ações de coordenadores na promoção da educação ambiental junto aos cursos superiores de Administração e de Gestão. Para tanto, realizou-se uma pesquisa de campo, com os coordenadores de cursos de Bacharelado em Administração e Cursos Superiores de Tecnologia em Gestão e Negócios, dos municípios de São Bernardo do Campo e de São Caetano do Sul (SP). O estudo fez-se por meio de entrevista aos coordenadores sobre como conduzem a educação ambiental nas suas áreas. Foi possível constatar a insuficiência das ações relativas à educação ambiental, que se restringe à oferta de uma disciplina, a qual não é a forma recomendada pela Política Nacional de Educação Ambiental (PNEA). Observou-se, ainda, a plena consciência dos entrevistados acerca da necessidade de fortalecimento das ações destinadas à educação ambiental dos futuros profissionais das áreas em consideração. Constataram-se equívocos na sua interpretação do conceito de transversalidade, expresso na Lei de Diretrizes e Bases da Educação (LDB), em que se apoia a PNEA para promover a educação ambiental.
\end{abstract}

Palavras-chave: Avaliação educacional. Educação ambiental. Políticas públicas.

\begin{abstract}
The objective of this research is to highlight the actions of coordinators to promote environmental education along the high education courses of Administration and Management. For this purpose, we carried out a field survey, with the coordinators of Business and Business Management Technology courses in the municipalities of São Bernardo do Campo and São Caetano do Sul (São Paulo State). The study was carried out through an interview with the coordinators on how they conduct environmental education in their areas. It was possible to verify the insufficiency of the actions related to environmental education, which is restricted to the offer of a discipline, which is not the form recommended by the National Environmental Education Policy (PNEA). It was also observed that respondents were fully aware of the need to strengthen actions aimed at environmental education for future professionals in the areas under consideration. There were mistakes in their interpretation about the concept of transversality, expressed in the Law of Directives and Bases of Education (LDB), which supports the PNEA to promote environmental education.
\end{abstract}

Keywords: Educational evaluation. Environmental education. Public policy.

\section{Resumen}

El objetivo de esta investigación es poner en evidencia las acciones de coordinadores en la promoción de la educación ambiental en los cursos superiores de Administración y Gestión. Para ello, se realizó un estudio de campo, con los coordinadores de los cursos de Administración y Tecnología en Gestión y Negocios, de los

\footnotetext{
${ }^{1}$ Professor de Administração da Universidade Federal de Mato Grosso do Sul (EFMS). E-mail: ivan.maia@ufms.br.

2 Professor de Administração da Faculdade de Tecnologia Termomecanica. E-mail: diogomgm@gmail.com.

3 Professora de Administração da Universidade Municipal de São Caetado do Sul (USCS). E-mail: raquel.pereira@prof.uscs.edu.br.
} 
municipios São Bernardo do Campo y São Caetano do Sul (SP). El estudio se hizo por medio de entrevistas a los coordinadores sobre la forma como conducen la educación ambiental en sus áreas respectivas. Fue posible constatar la insuficiencia de las acciones relativas a la educación ambiental, que se restringe a una disciplina, lo que no corresponde a lo establecido en la Política Nacional de Educación Ambiental (PNEA). Se observó, también, la plena consciencia de los entrevistados sobre la necesidad de fortalecerse las acciones destinadas a la educación ambiental de los futuros profesionales de las áreas en consideración. Se constataron equivocaciones en su interpretación del concepto de transversalidad expresado en la Ley de Directrices y Bases (LDB), en que se apoya la PNEA para promover la educación ambiental.

Palabras-clave: Evaluación educativa. Educación ambiental. Políticas públicas.

\section{Introdução}

Instituída pela Lei no 9.795, de 27 de abril de 1999, a Política Nacional de Educação Ambiental (PNEA) estabelece que a educação ambiental seja um componente essencial e permanente da educação nacional. Sua presença deve estar, de forma articulada, em todos os níveis e modalidades do processo educativo (BRASIL, 1999).

No que se refere à operacionalização da política, a própria PNEA determina que a educação ambiental seja desenvolvida como uma prática educativa integrada, contínua e permanente em todos os níveis e modalidades do ensino formal. A recomendação não exige a implantação de uma disciplina específica no currículo de ensino, o que enfraquece a amplitude e urgência necessária do tema.

Nesta direção, o Ministério da Educação, por meio do Sistema de Avaliação do Ensino Superior, ampliou o número de requisitos legais que constam no instrumento de avaliação utilizado para autorização, reconhecimento e renovação de cursos de graduação. Os indicadores específicos passaram de 05 para 10 em 2011 e para 13 em 2012, quando foi também incluída uma questão para verificar se há integração da educação ambiental às disciplinas do curso, de modo transversal, contínuo e permanente (BRASIL, 2011).

A promoção da educação ambiental na educação superior se tornou uma condição sine qua non para a autorização e reconhecimento de todos os cursos de graduação no Brasil. Desde que foi instituída a PNEA, muitos estudos foram realizados, buscando a compreensão dos alunos de cursos de graduação específicos, principalmente os de Administração, acerca da educação ambiental, como os realizados por Tozzoni-Reis (2001); Barbieri (2004); Oliveira, Oliveira e Costa (2010); Santos et al. (2013) e Silva (2013).

Nesse mesmo sentido, o Ministério da Educação realizou o Mapeamento da Educação Ambiental em 27 instituições brasileiras de educação superior. Buscaram-se elementos para discussão sobre políticas públicas (RUPEA, 2005), os quais indicaram uma associação ainda muito grande entre a educação ambiental e as disciplinas clássicas das ciências naturais. Foi 
apontada a sua inserção nas discussões das ciências humanas nos cursos de bacharelado ou licenciatura em Geografia, Pedagogia ou Turismo.

Pelos resultados das pesquisas há pouco citadas, observa-se, de maneira geral, a convergência dos estudos para um cenário de insuficiência das ações destinadas à educação ambiental nos cursos de graduação. Essa carência ocorre seja pelo movimento da educação ambiental, que não é a forma recomendada pela PNEA, mas também pela ausência, em muitos casos, de qualquer discussão acerca da problemática ambiental vigente.

Outra questão que vale destacar são as mudanças ocorridas no ensino superior brasileiro, entre elas a instituição do Sistema Nacional de Avaliação do Ensino Superior (SINAES), regulador da qualidade do ensino superior. Essa avaliação se refere à educação ambiental desde 2012. Também é preciso destacar o surgimento de nova proposta de educação superior, que inclui os Cursos Superiores de Tecnologia (CST), para além dos tradicionais cursos de bacharelado e de licenciatura.

De acordo com o Censo da Educação Superior, realizado anualmente pelo Ministério da Educação (MEC), entre 2000 e 2011, o percentual de ingressantes aos CST aumentou 547\%, somados os de instituições privadas e públicas do estado de São Paulo (BRASIL, 2012). Os CST se diferenciam dos cursos de bacharelado e licenciatura pela proposta pedagógica e pelo público alvo. Esses cursos estão divididos, segundo a Portaria n ${ }^{\circ} 1.024$, de 11 de maio de 2006, em 112 graduações diferentes, organizadas em 13 eixos tecnológicos (BRASIL, 2006). Considerando os CST do eixo de gestão e negócios, dados do Censo da Educação Superior mostram que em 2000 havia 2.712 cursos, enquanto que em 2011 esses cursos somavam 3.744, entre as modalidades presencial e a distância (BRASIL, 2012).

Diante de tal crescimento, emerge como problema dessa pesquisa conhecer quais as ações concretizadas pelos coordenadores dos cursos para a promoção da educação ambiental, em atendimento às normas instituídas pela Política Nacional de Educação Ambiental. Consideram-se os cursos de Administração e os diversos CST da área de Gestão e Negócios oferecidos nos municípios de São Bernardo do Campo (SP) e de São Caetano do Sul (SP). Esses dois municípios foram escolhidos em função da facilidade de acesso.

Diante desse problema e desses critérios, foi realizada uma pesquisa de campo, que envolveu os coordenadores dos cursos participantes do ENADE 2012, que são os CST da área de Gestão e Negócios, além dos bacharelados em Administração.

O objetivo da pesquisa é evidenciar as ações dos coordenadores de cursos, para a promoção da educação ambiental, juntos aos cursos que coordenam. 
A apresentação do estudo está dividida em cinco partes: esta primeira introdutória, em que são expostos o contexto e objetivo do estudo; a seção 2, que apresenta o referencial teórico para o entendimento da PNEA e dos resultados dos principais estudos já realizados; a seção 3, que apresenta os procedimentos metodológicos utilizados; a apresentação e a análise dos resultados na seção 4; e a seção 5, contendo as considerações finais.

\section{Revisão bibliográfica}

\subsection{A Política Nacional de Educação Ambiental}

A PNEA, por meio da Lei $n^{\circ} 9.795$, de 27 de abril de 1999, estabelece que a educação ambiental seja um componente essencial e permanente da educação nacional, devendo estar presente, de forma articulada, em todos os níveis e modalidades do processo educativo, em caráter formal e não-formal (BRASIL, 1999).

Quanto aos seus objetivos, em seu artigo $5^{\circ}$, estabelece que a PNEA promova:

I. o desenvolvimento de uma compreensão integrada do meio ambiente em suas múltiplas e complexas relações, envolvendo aspectos ecológicos, psicológicos, legais, políticos, sociais, econômicos, científicos, culturais e éticos;

II. a garantia de democratização das informações ambientais;

III. o estímulo e o fortalecimento de uma consciência crítica sobre a problemática ambiental e social;

IV. o incentivo à participação individual e coletiva, permanente e responsável, na preservação do equilíbrio do meio ambiente, entendendo-se a defesa da qualidade ambiental como um valor inseparável do exercício da cidadania;

V. o estímulo à cooperação entre as diversas regiões do país, em níveis micro e macrorregionais, com vistas à construção de uma sociedade ambientalmente equilibrada, fundada nos princípios da liberdade, igualdade, solidariedade, democracia, justiça social, responsabilidade e sustentabilidade;

VI. o fomento e o fortalecimento da integração com a ciência e tecnologia;

VII. o fortalecimento da cidadania, autodeterminação dos povos e solidariedade como fundamentos para o futuro da humanidade.

Entende-se por educação formal aquela escolarizada e desenvolvida no âmbito dos currículos das instituições de ensino públicas e privadas, englobando a educação básica, educação superior, educação de jovens e adultos, educação especial e educação profissional.

Para a educação formal, a PNEA estabelece que a educação ambiental seja desenvolvida como uma prática educativa integrada, contínua e permanente em todos os níveis e modalidades do ensino formal, e não deve ser implantada como disciplina específica no currículo de ensino, mas por meio de abordagem interdisciplinar e transversal nas disciplinas oferecidas aos estudantes. 
A partir da elaboração da Lei de Diretrizes e Bases da Educação (LDB), de 1996, foram definidos Parâmetros Curriculares Nacionais (PCNs) que, por sua vez, orientam para a aplicação da transversalidade. No âmbito dos PCNs, a transversalidade diz respeito à possibilidade de se estabelecer, na prática educativa, uma relação entre aprender conhecimentos teoricamente sistematizados (aprender sobre a realidade) e as questões da vida real e de sua transformação (aprender na realidade e da realidade). Não se trata de trabalhá-los paralelamente, mas de trazer para os conteúdos e para a metodologia da área a perspectiva dos temas (BRASIL, 1996).

Por educação ambiental não formal, entendem-se as ações e as práticas educativas voltadas à sensibilização da coletividade sobre as questões ambientais e à sua organização e participação na defesa da qualidade do meio ambiente. Portanto, todo e qualquer meio de educação ambiental extraescolar, a exemplo do que ocorre no âmbito de empresas, a realizada pelos meios de comunicação, entre outras formas.

Diante desta breve apresentação da PNEA, torna-se claro o objetivo e a forma proposta para a operacionalização da educação ambiental, apresentada a seguir.

\subsection{A educação ambiental na educação superior}

Após a instituição da PNEA, muitos estudos foram realizados a fim de sustentar o conteúdo e, principalmente, a maneira de se promover a educação ambiental formal.

A pesquisadora Tozzoni-Reis (2001) discute os pressupostos teóricos presentes na formação ambiental dos cursos de graduação e sugere princípios metodológicos de organização curricular desses cursos, que se resumem ao uso de projetos interdisciplinares. Segundo ela, o desenvolvimento do trabalho interdisciplinar exige dos formadores e das instituições de ensino uma mudança de paradigma, passando da atual concepção de educação fragmentada, como uma disciplina com muito conteúdo, para o paradigma da totalidade histórica, que consiste na ideia de uma educação mais ampla, passando pelos campos pedagógico, político, social e científico.

Barbieri (2004) levanta questões problemáticas relacionadas com a implementação da educação ambiental em cursos de graduação em Administração, conforme estabelece a legislação brasileira. Segundo o autor, um dos maiores problemas da educação ambiental nos cursos de graduação em Administração são as dificuldades para implementar abordagens multi, inter e transdisciplinares.

O pesquisador também constatou em suas pesquisas que, normalmente, há nos cursos de graduação — com a finalidade de atender a PNEA —, a presença de uma disciplina 
denominada Gestão Ambiental ou de nomenclatura similar, mas assevera que tal disciplina não pode ser confundida com a educação ambiental, nem a substituir. Defende a ideia de que o oferecimento de tal disciplina seja necessário e que deve permanecer enquanto as questões ambientais não estiverem, adequadamente, tratadas pelas demais disciplinas.

Na mesma direção, Pinto (2004) descreve os caminhos percorridos em Portugal para a difusão da educação ambiental, que inclui uma reforma no sistema educativo e a criação de temas e disciplinas relacionadas ao meio ambiente na educação básica e na educação superior.

Ainda sobre a disciplina Gestão Ambiental, oferecida nos cursos de Administração com o intuito de atender a PNEA, Oliveira, Oliveira e Costa (2010) avaliaram a importância atribuída por professores de instituições de ensino superior em Administração a esta disciplina. Por meio de um survey que envolveu 41 professores de diferentes instituições na cidade de Fortaleza (CE), os autores concluíram que, embora os professores concordem sobre a importância da disciplina Gestão Ambiental para os cursos de Administração, o nível de envolvimento dos professores com a área foi baixo.

Em uma pesquisa envolvendo alunos do curso de Administração da Universidade Positivo, Santos et al. (2013) buscaram compreender o impacto da educação ambiental durante o curso sobre os alunos como futuros administradores. Concluiu-se que o seu impacto tem sido pouco satisfatório na formação dos alunos. Os autores constataram que 47,8\% dos pesquisados não teve contato algum com o tema socioambiental durante o ensino médio e que $36,7 \%$ dos alunos permaneceram sem esse contato, mesmo na universidade.

Silva (2013) apresentou a experiência de inserção da educação ambiental no currículo do curso de graduação em Pedagogia, da Universidade Federal do Pará, a qual indicou a sua presença ampliada qualitativa e quantitativamente, sem, contudo, se configurar como uma presença regular e sistemática.

Além da PNEA e dos estudos que focam na forma com que é desenvolvida a educação ambiental, há também pesquisas que debatem os caminhos para o seu desenvolvimento, defendendo a ideia de que a educação ambiental e a sustentabilidade sejam um compromisso de todos os funcionários das instituições de ensino superior, extrapolando a relação entre professores e alunos (LOZANO et al., 2013).

\section{Metodologia}

Para atingir o objetivo do estudo, que é evidenciar as ações dos coordenadores na promoção da educação ambiental nos cursos que coordenam, realizou-se uma pesquisa de 
campo ligada aos cursos de bacharelado em Administração e CST do eixo de Gestão e Negócios. Delimitou-se o estudo aos municípios de São Bernardo do Campo (SP) e São Caetano do Sul (SP), localizados na Região do ABC, na Região Metropolitana de São Paulo (SP). O estudo foi classificado como exploratório que, segundo Gil (2006), é a pesquisa que tem a finalidade de desenvolver, esclarecer e modificar conceitos e ideias, visando à formulação de problemas mais precisos ou hipóteses pesquisáveis para estudos posteriores.

A amostra selecionada foi não-probabilística e intencional, pois teve a finalidade de envolver cursos de Administração e CST da área de Gestão e Negócios que haviam participado da avaliação promovida pelo Sistema Nacional de Avaliação do Ensino Superior (SINAES), que envolve o Exame Nacional de Desempenho do Ensino Superior (ENADE). A Tabela 1 apresenta o número total de cursos e o tamanho da amostra.

Tabela 1 - População alvo e amostra da Pesquisa

\begin{tabular}{|c|c|c|c|c|c|c|}
\hline \multirow[t]{2}{*}{ Cursos } & \multicolumn{3}{|c|}{$\begin{array}{c}\text { São Bernardo do Campo } \\
\text { (SP) }\end{array}$} & \multicolumn{3}{|c|}{$\begin{array}{c}\text { São Caetano do Sul } \\
\text { (SP) }\end{array}$} \\
\hline & Total & Amostra & $\%$ & Total & Amostra & $\%$ \\
\hline Administração & 06 & 04 & 67 & 04 & 02 & 50 \\
\hline CST em Gestão Comercial & 01 & 01 & 100 & 01 & 01 & 100 \\
\hline CST em Gestão Financeira & 04 & 01 & 25 & 01 & 01 & 100 \\
\hline $\begin{array}{c}\text { CST em Gestão de Recursos } \\
\text { Humanos }\end{array}$ & 04 & 01 & 25 & 01 & 01 & 100 \\
\hline CST em Logística & 04 & 01 & 25 & 02 & 01 & 50 \\
\hline CST em Marketing & 03 & 01 & 33 & 02 & 01 & 50 \\
\hline CST em Processos Gerenciais & 04 & 02 & 25 & 01 & 01 & 100 \\
\hline CST em Secretariado Executivo & 01 & 0 & 0 & 0 & 0 & 0 \\
\hline Total & 27 & 11 & 41 & 12 & 08 & 67 \\
\hline
\end{tabular}

Fonte: Dados desta pesquisa.

A abordagem da pesquisa foi qualitativa, conduzida por meio de entrevistas semiestruturadas com os coordenadores dos cursos escolhidos, além de contatos por e-mail 
institucional e por telefone, entre maio e junho de 2014. A cada um dos coordenadores, perguntou-se, em essência, como é promovida a educação ambiental no curso que coordena.

Os pesquisadores recebiam as respostas e imediatamente enviavam outro e-mail solicitando exemplos concretos acerca da operacionalização das ações mencionadas pelos coordenadores, e em alguns casos, era solicitada a ementa das disciplinas citadas pelos coordenadores.

Desta maneira, foi possível realizar o aprofundamento do levantamento das informações, além de obter uma taxa de retorno razoável dos respondentes: $67 \%$ em São Caetano do Sul (SP) e 41\% em São Bernardo do Campo (SP), conforme Tabela 1.

\section{Apresentação e análise dos resultados}

Por meio da pesquisa de campo realizada em São Bernardo do Campo (SP), constatouse que os coordenadores consideram, de maneira predominante, que o oferecimento de disciplinas relacionadas ao desenvolvimento sustentável e ao meio ambiente atende às exigências da Política Nacional de Educação Ambiental (PNEA).

Uma ação promotora da educação ambiental mencionada pelo coordenador do curso de Administração de uma instituição de ensino de São Bernardo do Campo (SP) foi a realização de dois eventos periódicos e sistemáticos, em que são abordadas questões ambientais e de sustentabilidade com professores e alunos. O coordenador do curso destaca:

Efetuamos anualmente um evento denominado EPA, encontro de profissionais e alunos, nos eventos trazemos palestrantes que discorrem sobre variados temas, contudo sempre incluímos palestras voltadas ao meio ambiente e desenvolvimento sustentado.

Constatou-se também que alguns eventos possuem como temática principal a sustentabilidade e o meio ambiente; são promovidos pela instituição de ensino, com a participação dos alunos de todos os cursos, como o exemplo do evento citado pelo coordenador de um curso de Administração de São Bernardo do Campo (SP): "No dia da responsabilidade social universitária, fazemos ações voltadas ao respeito do ser humano e também do meio ambiente".

Também envolvendo um curso de Administração de São Bernardo do Campo (SP), observou-se que temas relacionados ao meio ambiente são propostos para que os alunos desenvolvam seus trabalhos de conclusão de cursos, conforme pode ser evidenciado pela fala do coordenador: 
Nos trabalhos de conclusão de curso incentivamos temas voltados às questões ambientais, tais como reuso da água, economia sustentável, reciclagem de pneus, pósconsumo, dentre outros.

O coordenador de um curso de Processos Gerenciais, em São Bernardo do Campo (SP) mencionou um evento realizado pelo curso, denominado "Jornada da Gestão Ambiental", que envolve coordenador, professores e alunos. Além disso, alegou oferecer, periodicamente, pela modalidade a distância, uma oficina intitulada "Educação Ambiental", com carga horária de vinte horas.

O Quadro 1 traz um retrato das ações promotoras da educação ambiental pelos cursos de São Bernardo do Campo (SP). A oferta de uma disciplina da área e os eventos se destacam.

Quadro 1 - Promoção da Educação Ambiental em São Bernardo do Campo (SP)

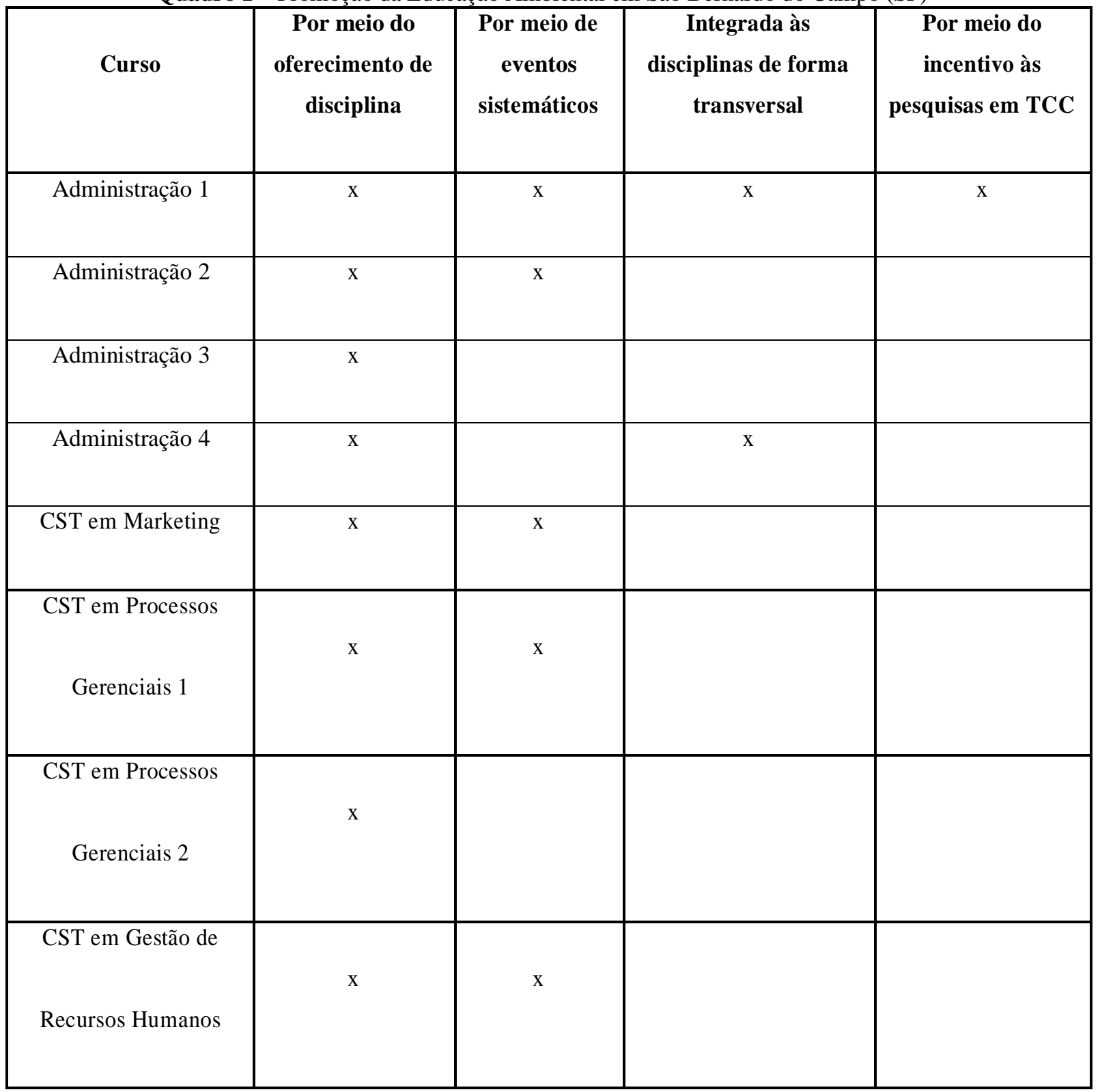




\begin{tabular}{|c|c|c|c|c|} 
CST em Gestão & $\mathrm{x}$ & $\mathrm{x}$ & & \\
Financeira & $\mathrm{x}$ & $\mathrm{x}$ & & \\
\hline CST em Gestão & & & & \\
Comercial & $\mathrm{x}$ & $\mathrm{x}$ & & \\
\hline CST em Logística & & & & \\
\hline
\end{tabular}

Fonte: Resultados desta pesquisa.

Em São Caetano do Sul (SP), houve 67\% de retorno dos contatos com a coordenação, contanto, observou-se que a promoção da educação ambiental pelos coordenadores se resume no oferecimento de uma disciplina na grade curricular dos cursos.

No que se refere ao conceito de transversalidade, mencionado pela PNEA, observou-se certa confusão por parte dos coordenadores dos cursos superiores de tecnologia (CST) em Marketing; Gestão de Recursos Humanos; Gestão Financeira; Gestão Comercial; e Logística. Pelo exposto por um dos coordenadores, há evidências de que não há compreensão do conceito de transversalidade:

Como a disciplina introduzida na grade deste semestre para todos os cursos da escola tecnológica de negócios é considerada transversal, ou seja, atende a todos os cursos, entendemos que todos devam ter conhecimento a respeito do assunto.

Pelo que diz o coordenador, observa-se que acredita que o fato de a disciplina ser oferecida em todos os cursos da instituição de ensino faz com que ela seja transversal. Tal concepção não condiz com a proposta da PNEA, que exige a promoção da educação ambiental em todas as disciplinas do curso, de maneira transversal. A falta da exigência do PNEA de uma disciplina da área de educação ambiental não garante que o tema seja citado durante os cursos.

O coordenador de um dos cursos de Administração destacou que praticamente todas as disciplinas, de uma forma ou de outra, tratam questões ambientais em seus trabalhos e projetos, desenvolvidos sob orientação da coordenação. Conforme o coordenador:

Nós temos uma disciplina no curso que versa sobre Sustentabilidade, além de, em todos os nossos trabalhos, este tema estar presente no cotidiano dos nossos estudantes.

O Quadro 2 apresenta as ações promotoras da educação ambiental nos cursos de São Caetano do Sul (SP), com destaque para o oferecimento de disciplina sobre o tema. 
Quadro 2 - Promoção da Educação Ambiental de São Caetano do Sul (SP)

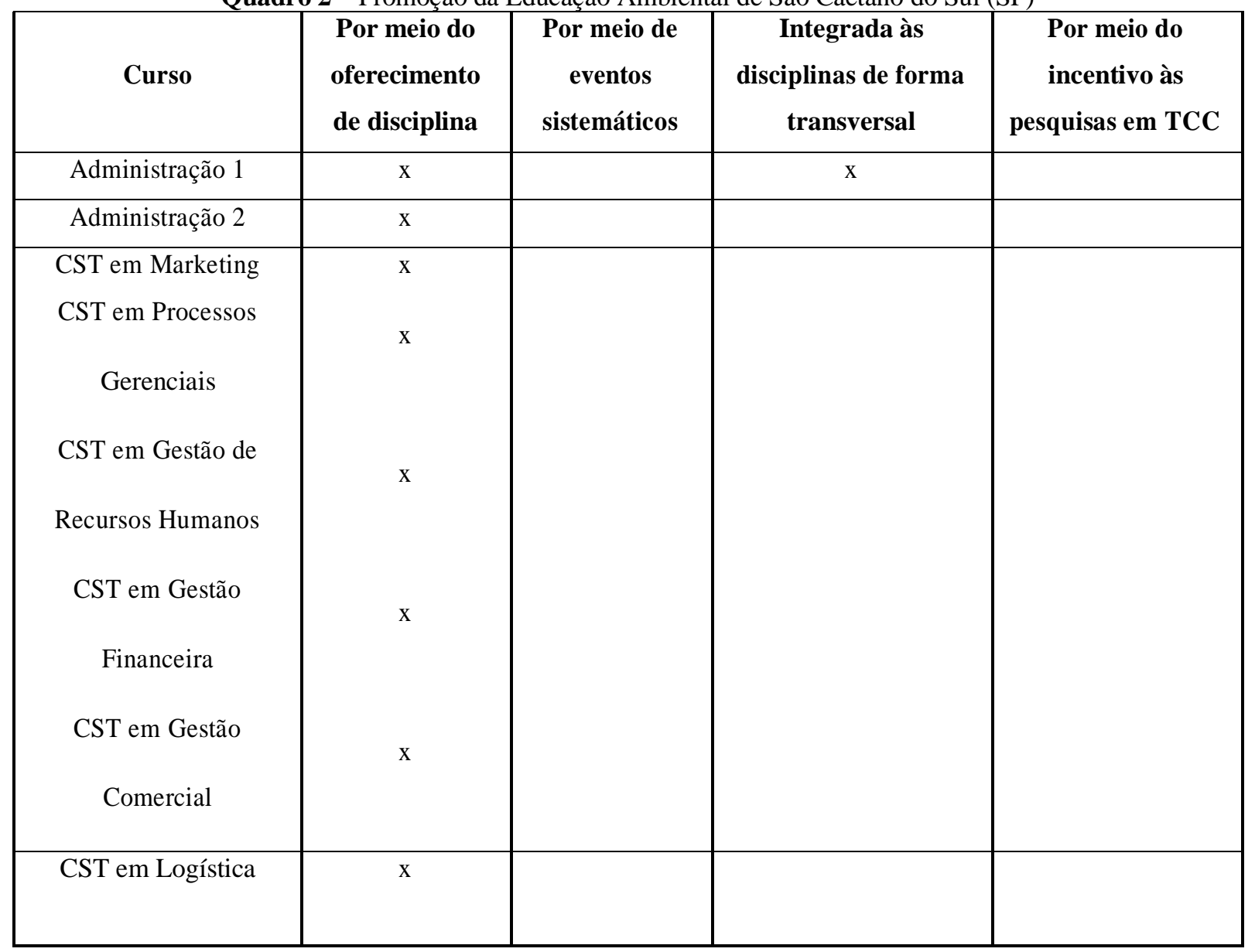

Fonte: Resultados desta pesquisa.

De todos os coordenadores participantes da pesquisa (108), nenhum deles negou a promoção da educação ambiental. O tema era esperado pelos pesquisadores, por ser esta, desde 2012, uma condição normativa para a autorização e reconhecimento de todos os cursos de graduação no Brasil. Tal fato deve-se ao discutido no referencial teórico deste trabalho, acerca da evolução do instrumento de avaliação do Sistema Nacional de Avaliação do Ensino Superior (SINAES).

Desde os estudos de Barbieri (2004), algumas coisas se modificaram, como a variedade de disciplinas criadas para a promoção da educação ambiental nos cursos de Administração que, conforme o autor, se resumia à disciplina intitulada Gestão Ambiental.

Os títulos das disciplinas mencionadas e os cursos dos quais fazem parte, tanto em São Bernardo do Campo (SP) quanto em São Caetano do Sul (SP), são apresentados pela Tabela 2. São em total 19 cursos: 
A educação ambiental nos cursos superiores de Tecnologia da Área de Gestão e Negócios e nos Bacharelados em Administração

Tabela 2 - Distribuição de frequências das disciplinas oferecidas pelos cursos

\begin{tabular}{|c|c|}
\hline Disciplinas & Cursos \\
\hline \multirow{7}{*}{ Sustentabilidade Socioambiental } & Administração \\
\hline & CST em Gestão Comercial \\
\hline & Gestão de Recursos Humanos \\
\hline & Gestão Financeira \\
\hline & Logística \\
\hline & Marketing \\
\hline & Processos Gerenciais \\
\hline \multirow{6}{*}{$\begin{array}{c}\text { Responsabilidade Social e Meio } \\
\text { Ambiente }\end{array}$} & CST em Gestão Comercial \\
\hline & Gestão de Recursos Humanos \\
\hline & Gestão Financeira \\
\hline & Logística \\
\hline & Marketing \\
\hline & Processos Gerenciais \\
\hline \multirow{2}{*}{$\begin{array}{l}\text { Gestão Socioambiental e } \\
\text { Sustentabilidade }\end{array}$} & Administração \\
\hline & CST em Processos Gerenciais \\
\hline $\begin{array}{c}\text { Meio Ambiente, Políticas e Legislação } \\
\text { Ambiental }\end{array}$ & Administração \\
\hline $\begin{array}{c}\text { Gestão e Práticas de Responsabilidade } \\
\text { Social }\end{array}$ & Administração \\
\hline $\begin{array}{c}\text { Desenvolvimento Sustentado e Impactos } \\
\text { Ambientais }\end{array}$ & Administração \\
\hline Planejamento e Gestão Ambiental & Administração \\
\hline
\end{tabular}

Fonte: Resultados da pesquisa.

Os resultados deste estudo confirmam os achados de Tozzoni-Reis (2001), Barbieri (2004) e o Mapeamento da Educação Ambiental em Instituições Brasileiras de Educação Superior: elementos para discussão sobre políticas públicas (RUPEA, 2005), acerca do processo de tornar a educação ambiental uma disciplina dos cursos de Administração. Além disso, o estudo concorda com Silva (2013), quando afirma que houve crescimento qualitativo e quantitativo da educação ambiental na educação superior, mesmo que este não esteja de acordo com as orientações da PNEA.

\section{Considerações finais}

Diante dos resultados da pesquisa, observa-se, de maneira geral, a insuficiência das ações promovidas para a educação ambiental nos cursos de bacharelado em administração e 
nos cursos superiores de tecnologia (CST) da área de Gestão e Negócios, por causa do movimento de tornar a educação ambiental uma disciplina, que não é a forma recomendada pela Política Nacional de Educação Ambiental (PNEA).

Talvez, a ausência da exigência de uma disciplina possa ser um equívoco conceitual dessa política. Isso porque o entendimento de conceitos para divulgar a educação ambiental tais como a transversalidade - ainda não está consolidado na área da educação, como citou o coordenador de diversos cursos de São Caetano do Sul (SP).

Observou-se consciência plena dos coordenadores acerca da necessidade de se promover a educação ambiental, entretanto, constataram-se equívocos na interpretação do conceito de transversalidade, que é a orientação da PNEA para a promoção da educação ambiental.

Ao considerar os resultados encontrados — associados à criação do indicador normativo do instrumento de avaliação de cursos do Sistema Nacional de Avaliação do Ensino Superior (SINAES), que desde 2012 é condição sine qua non para a autorização e reconhecimento de cursos de graduação - , este estudo contribui para que os mantenedores e coordenadores das instituições de ensino superior brasileiras possam entender a forma mais adequada de promoção da educação ambiental nos cursos de graduação, que é a inserção do tema em todas as disciplinas.

Este trabalho confirmou os estudos de Barbieri (2004) e de Oliveira, Oliveira e Costa (2010), que focam a promoção por meio de uma disciplina, frequentemente, com o nome de Gestão Ambiental. Projetos interdisciplinares ligados à promoção da educação ambiental, como cita Tozzoni-Reis (2001), não foram encontrados. A influência da educação ambiental na formação dos alunos (SANTOS et al., 2013), assim como a experiência de inserção da educação ambiental no currículo dos cursos (SILVA, 2013) não foram considerados nesta pesquisa.

Embora os procedimentos metodológicos tenham atendido ao propósito desta pesquisa, há limitações que devem ser apontadas, tais como a impossibilidade de generalização de resultados, uma vez que se trabalhou com o recorte geográfico de instituições de ensino de São Bernardo do Campo (SP) e de São Caetano do Sul (SP), assim como da área de atuação dos cursos. Tal limitação não minimiza a força dos resultados deste estudo, mas representa hipóteses para novas e futuras pesquisas nas áreas delimitadas pelo presente estudo e nas demais áreas.

\section{Referências}


BARBIERI, J. C. A Educação ambiental e a gestão ambiental em cursos de graduação em administração: objetivos, desafios e propostas. Revista de Administração Pública, Rio de Janeiro, v. 38, n. 6, p. 919-46, nov./dez. 2004.

BRASIL. Lei n. 9.394/96, de 20 de dezembro de 1996. Estabelece as diretrizes e bases da educação nacional. Disponível em www.mec.gov.br. Acesso em 10/02/2014.

BRASIL. Lei n ${ }^{\circ}$ 9.795, de 27 de abril de 1999. Dispõe sobre a Educação Ambiental, institui a Política Nacional de Educação Ambiental e dá outras providências. Diário Oficial da União, Brasília, 28 de abril de 1999.

BRASIL. Ministério da Educação. RUPEA. Relatório final da pesquisa: Mapeamento da Educação Ambiental em instituições brasileiras de Educação Superior: elementos para discussão sobre políticas públicas. Brasília: MEC, 2005.

BRASIL. Ministério da Educação. Portaria no 1024/2006. Disponível em:

http://mecsrv70.mec.gov.br/catalogo_cursos/index.php?pagina=portaria_1024. Acesso em: 09 de junho de 2014.

BRASIL. Ministério da Educação. Portaria Normativa ${ }^{0}$ 1741. Aprova, em extrato, os indicadores do Instrumento de Avaliação de Cursos de Graduação nos graus de tecnólogo, de licenciatura e de bacharelado para as modalidades: presencial e a distância, do Sistema Nacional de Avaliação da Educação Superior - SINAES. Diário Oficial da União, Brasília, 12 de dezembro de 2011.

BRASIL. Ministério da Educação. Instituto Nacional de Estudos e Pesquisas Educacionais Anísio Teixeira (Inep). Censo da educação superior. Brasília: Inep, 2012.

GIL, A. C. Métodos e técnicas de pesquisa social. 5. ed. São Paulo: Atlas, 2006.

LOZANO, R.; LUKMAN, R.; LOZANO, F.J; HUISINGH, D.; LAMBRECHTZ, W. Declarations for sustainability in higher education: becoming better leaders, through addressing the university system. Journal of Cleaner Production, [s.l.], v. 48, p. 10-19, jun. 2013.

OLIVEIRA, L. G. L; OLIVEIRA, D. M.; COSTA, F. J. A Gestão ambiental nos cursos de Administração: uma análise da perspectiva dos professores. Revista de Administração da UFSM, Santa Maria, v. 3, n. 2, p. 205-218, maio/ago. 2010.

PINTO, J. R. A Educação ambiental em Portugal: raízes, influências, protagonistas, principais ações. Revista Educação Sociedade e Culturas. Porto, Portugal, p. 151-164. 2004.

SANTOS, D. F.; CARLI, V. R.; SANTOS A. F.; CORREA, M. D.; ANTONOVZ, T. Educação ambiental no curso de Administração. Revista Meio Ambiente e Sustentabilidade, Curitiba, v. 4, n. 2, p. 81-98, jul./dez. 2013.

SILVA, M. L. A Educação ambiental no ensino superior brasileiro: do panorama nacional às concepções de alunos (as) de pedagogia na Amazônia. Revista Eletrônica do Mestrado em Educação Ambiental, Rio Grande, v. especial, p. 18-33, mar. 2013. 
TOZZONI-REIS, M. F. C. Environmental education: theoretical references in higher education. Interface - Comunicação, Saúde, Educação, Botucatu, v. 5, n. 9, p. 33-50, ago. 2001. 